REVIEW ARTICLE

\title{
Fibroids and Infertility: The Added Value of Three-dimensional Ultrasound
}

\author{
Sanja Kupesic Plavsic
}

\begin{abstract}
Uterine fibroids, benign monoclonal tumors of the uterine smooth muscle cells and fibrous connective tissue, are the most common tumors of the female pelvis, occurring in about $20-30 \%$ of women of reproductive age. The cumulative rate of uterine fibroids increases with age, with a tendency of slower increase at older reproductive age. Fibroids may be of various sizes, single or multiple, and are described based on their relationship to the uterine cavity. Those located within the myometrium are called intramural and are considered the most common, occurring in about $58-79 \%$ of all patients, while the other locations are submucous which eventually may become intracavitary and subserous fibroids. According to the American Society for Reproductive Medicine (ASRM), uterine myomas are associated with infertility in 5-10\% of cases and may be responsible for 2-3\% of infertility cases. The growth of fibroids during pregnancy cannot be predicted. Majority of the fibroids' growth occurred in the first trimester. Imaging techniques used for the diagnosis of uterine fibroids include transabdominal and transvaginal twodimensional (2D) and three-dimensional (3D) ultrasound, saline infusion sonography (SIS), and magnetic resonance imaging (MRI). Sonographic assessment of the uterine fibroids includes determination of their number, location, echotexture, and size, by measuring the three maximum diameters (length, width, and height). Serial examinations are necessary to document the interval growth and change in morphology. Combining the advantages of multiple imaging modalities: ultrasound as a noninvasive, nonirradiation, and inexpensive method, and volume acquisition known from CT and MR imaging technologies, 3D ultrasound and 3D power Doppler angiography have become valuable diagnostic tools for the assessment of uterine fibroids. By providing multiplanar imaging, 3D ultrasound not only gives an additional dimension to the uterine scan but also provides a similar quality and less expensive alternative to MRI. Automated volume acquisition minimizes the subjectivity of the ultrasound assessment and can be used for retrospective analysis.
\end{abstract}

Keywords: Infertility, Three-dimensional power Doppler, Three-dimensional ultrasound, Uterine fibroids.

Donald School Journal of Ultrasound in Obstetrics and Gynecology (2019): 10.5005/jp-journals-10009-1606

\section{INTRODUCTION}

Uterine fibroids, benign monoclonal tumors of the uterine smooth muscle cells and fibrous connective tissue, are the most common tumors of the female pelvis, occurring in about $20-30 \%$ of women of reproductive age. ${ }^{1}$ Other frequently used descriptive terms for uterine fibroids are myoma, leiomyoma, and fibromyoma. The cumulative rate of uterine fibroids increases with age, with a tendency of slower increase at older reproductive age. The rate of occurrence is markedly greater in African Americans and patients with familial predisposition. ${ }^{2}$ It is estimated that a woman whose mother or sister was diagnosed with fibroid uterus has a $40 \%$ chance of developing a fibroid during her lifetime. ${ }^{3}$

Cytogenetic and molecular studies strongly suggest a genetic component in the etiology of uterine leiomyomas based on translocations found between chromosomes 12 and 14, 6 and 10, trisomy 12, and deletions of chromosomes 3 and 7.,4 The causes of leiomyomas are unknown; however, they typically arise after menarche and regress after menopause, implicating that estrogen $(E)$, progesterone $(P)$, and perimenopausal increase in luteinizing hormone (LH) act as promoters of their growth. Patients on tamoxifen treatment often experience an increase in leiomyoma growth, as well as patients with increasing body mass index (BMI). ${ }^{5,6}$ It is estimated that the risk of fibroids increases $21 \%$ with each $10 \mathrm{~kg}$ increase in body weight. Increased risk of fibroids is also noted in patients with an earlier age of menarche, patients who consume alcohol and caffeinated drinks, and is proportional to the duration of alcohol/coffee consumption and a number of drinks per day. ${ }^{4,6,7}$

Fibroids may be of various sizes, single or multiple, and are described based on their relationship to the uterine cavity. ${ }^{1,2}$
Department of Obstetrics and Gynecology, Paul L Foster School of Medicine, Texas Tech University Health Sciences Center, El Paso, Texas, USA Corresponding Author: Sanja Kupesic Plavsic, Department of Obstetrics and Gynecology, Paul L Foster School of Medicine, Texas Tech University Health Sciences Center, El Paso, Texas, USA, Phone: +1915 215 5065, e-mail: sanja.kupesic@ttuhsc.edu

How to cite this article: Kupesic Plavsic S. Fibroids and Infertility: The Added Value of Three-dimensional Ultrasound. Donald School J Ultrasound Obstet Gynecol 2019;13(4):220-228.

Source of support: Nil

Conflict of interest: None

Those located within the myometrium are called intramural and are considered the most common, occurring in about $58-79 \%$ of all patients. ${ }^{8-10}$ The submucous fibroids are located beneath the endometrium; they bulge into the uterine cavity and eventually may become intracavitary. Subserous fibroids are at the serosal surface of the uterus, projecting into the peritoneal cavity. Imaging techniques used for the diagnosis of uterine fibroids include transabdominal and transvaginal 2D and 3D ultrasound, SIS, and MRI. ${ }^{11}$

This paper reviews the role of different ultrasound modalities, with emphasis on 3D ultrasound in the assessment of infertile patients with uterine fibroids.

\section{Uterine Fibroids AND Infertility}

Uterine fibroids are heterogeneous lesions, and their relationship with infertility is commonly explained by mechanical factors such as distortion of the cervix and uterine cavity, impaired endometrial 
perfusion, increased and uncoordinated uterine contractility, and occlusion of the tubal ostia. ${ }^{12}$ Numerous studies attempting to assess this relationship failed due to small sample size, insufficient study design, and lack of correction for important confounding variables. ${ }^{13,14}$ While it is widely assumed that subserous fibroids do not affect fertility, patients with submucous fibroids show significantly lower pregnancy rates and their removal may enhance live birth rates. ${ }^{14}$ Currently, the most important unresolved issue is the assessment of the relationship between intramural fibroids and infertility, although it would appear logical that larger intramural fibroids interfere more with reproductive performance. Also, there is no clear evidence that myomectomy for intramural fibroids is beneficial to fertility. ${ }^{14}$

It has been reported that uterine contractility during the midluteal phase may play an important role in embryo implantation and pregnancy outcomes. Impaired uterine peristalsis noticed in some patients with intramural fibroids requires further evaluation. Yoshino et al. ${ }^{15}$ used a cine-mode-display MRI to assess the frequency of uterine contractions in mid-luteal phase of 95 patients with regular menstrual cycles and evidence of intramural fibroids not distorting uterine cavity. After separating patients into the two groups: (1) patients exhibiting low-frequency peristalsis ( $<$ two times in 3 minutes) and (2) patients with high-frequency peristalsis ( $\geq$ two times in 3 minutes), the authors found that none of the 22 patients with high-frequency peristalsis achieved pregnancy. Interestingly, the pregnancy rate in the group of 29 patients with low-frequency peristalsis was $34 \%$ $(p<0.005) .{ }^{15}$ These results indicate that the reproductive performance of patients with intramural fibroids may be compromised due to abnormal uterine contractility. Yan et al. ${ }^{16}$ performed a retrospective study of 249 patients with intramural fibroids not distorting uterine cavity who underwent an in vitro fertilization/intracytoplasmic sperm injection (IVF/ICSI) procedure. While no difference was detected in the IVF/ICSI outcomes between the patients with different sizes of the uterine fibroids, significantly impaired live birth rates $(p<0.043)$ were reported for the patients whose intramural fibroid largest diameter exceeded $2.85 \mathrm{~cm}^{16}$

According to the ASRM, uterine myomas are associated with infertility in $5-10 \%$ of cases and may be responsible for $2-3 \%$ of infertility cases. ${ }^{17,18}$ All confounding variables are difficult to control when searching for the impact of fibroids on infertility, and the association between reproductive dysfunction, miscarriage, and fibroids is not clearly established. More studies are needed to determine the clinical importance of the size, location, morphology, and proximity to the endometrium of intramural fibroids regarding the reproductive potential and pregnancy complications rate.

\section{Signs ANd Symptoms}

The symptomatology of the uterine fibroids is determined by the size, location, and extension of the degenerative changes. ${ }^{19}$ Many women with myomas remain asymptomatic.

Typically, submucous and intramural fibroids distorting the uterine cavity often result in abnormal uterine bleeding, clinically presenting as menorrhagia, dysmenorrhea, and intermenstrual spotting. Large uterine fibroids sometimes produce increasing abdominal girth associated with abdominal/pelvic discomfort or pain. An anterior leiomyoma often leads to urinary frequency and urgency, while posterior leiomyoma may be associated with lower back pain, rectal pressure, constipation, and rarely, leg discomfort and swelling.

\section{Hormonal Pattern}

Numerous studies have shown that $E$ and $P$ regulate most of the genes that encode growth factors which promote smooth muscle cells growth, while the use of $\mathrm{GnRH}$ agonist ( $\mathrm{GnRH}-\mathrm{a}$ ) lead to a rapid decrease in the uterine fibroid size. ${ }^{20-23}$ Bourlev et al. ${ }^{24}$ compared the growth pattern of the uterine leiomyomas during proliferative and secretory phases of the menstrual cycle by assessing the expression of sexsteroid receptors in their peripheral and central portions. Paired biopsy specimens confirm that during the secretory phase of the menstrual cycle, mitosis is significantly higher in the peripheral than in the central part of the uterine fibroids. During the proliferative phase, apoptosis shows the same pattern. ${ }^{24}$ Wei et al. ${ }^{25}$ compared the gene expression of selected genes in the uterine fibroids and normal myometrium. They confirmed that the expression of hypoxia-inducible factor-1 (HIF-1) is more pronounced in the peripheral portion of the fibroid compared to its central part. These observations illustrate that the fibroids typically grow from the periphery. ${ }^{25-28}$ However, sex steroids are not the only regulators of the uterine leiomyoma growth. Numerous studies have demonstrated the presence of mesoderm specific growth factors and their receptors in the myometrial and leiomyoma tissue. ${ }^{29-34}$

\section{Uterine Fibroids and Pregnancy}

Fibroid growth in pregnancy may be affected by increase in $E$ and $P$ levels, human chorionic gonadotropin (hCG), and uterine blood flow. Several ultrasound and Doppler studies attempted to assess the effect of fibroid size, location, and number on pregnancies. ${ }^{35-39}$ The conclusion of these studies is that the growth of fibroids during pregnancy cannot be predicted. Majority of the fibroids' growth occurred in the first trimester. ${ }^{35,36}$ Fibroids measuring $\leq 5 \mathrm{~cm}$ in diameter were more likely to remain stable in size, while larger fibroids were more likely to grow. The mean increase in fibroid volume during pregnancy is on average $12 \%$, and only a small proportion of the fibroids (22\%) increased by more than $25 \% .{ }^{37-39}$

Although majority of the patients with uterine fibroids do not report any complications, some authors reported slightly increased risk of complications such as miscarriage, preterm labor, antepartum bleeding, placental abruption, malpresentation, and dysfunctional labor. ${ }^{40-51}$ The available information is limited by inadequate methodology and study population selection, small sample size, different criteria used regarding the number, size, and location of the fibroids, limited number of adverse events, and inadequate adjustment of cofounding variables. ${ }^{52-56}$ However, studies consistently report that uterine leiomyoma are associated with an increased risk of cesarean delivery. ${ }^{57,58}$

\section{IMAGING}

Diagnosis of the uterine fibroids is based on enlargement, distortion of the contour, and textural changes of the uterus. ${ }^{59}$ Subserous and especially pedunculated fibroids can be mistaken for a number of conditions, including an ovarian neoplasm, bicornuate uterus, blind uterine horn, or even an ectopic pregnancy. Similarly, submucous and intracavitary fibroids are often confused with endometrial polyps. The use of complementary imaging modalities, such as different forms of ultrasound (2D and $3 D$ transabdominal and transvaginal ultrasound, 2D color Doppler and 3D power Doppler ultrasound), contrast ultrasound studies (e.g., 2D and 3D SIS), and MRI may be necessary to confirm the diagnosis. ${ }^{60}$ 


\section{D Ultrasound and Color Doppler FEATURES}

Sonographic assessment of the uterine fibroids includes determination of their number, location, echotexture, and size, by measuring the three maximum diameters (length, width, and height). Serial examinations are necessary to document the interval growth and change in morphology.

Leiomyomas arise from the uterine myometrium and consist of the fascicles of smooth muscle cells and extracellular matrix. ${ }^{61}$ Small fibroids typically appear as subtle changes in myometrial echogenicity. The increased amount of the extracellular matrix in an acellular area between the cells and a higher number of $E$ and $P$ receptors distinguishes the leiomyoma from the normal, surrounding myometrium. A well-delineated outline created by compressed muscle fibers forms a firm whorled surface, representing a pseudocapsule. ${ }^{62,63}$ On transabdominal and transvaginal ultrasound, this area appears as an echogenic peripheral zone, while on color Doppler ultrasound, it is visualized as a "ring of fire" (Fig. 1). ${ }^{64-66}$

Submucous fibroids are visualized as round or elongated hypoechogenic subendometrial lesions. Sometimes they extend into the uterine cavity, may become intracavitary, pedunculated, and may even prolapse through the cervix. ${ }^{63}$ They are differentiated from the endometrial polyps based on echogenicity and visualization in continuity with myometrium (Fig. 2). Color Doppler ultrasound typically reveals scattered vessels with moderate vascular impedance, although a wide range of vascularity signals may be obtained depending on the size, cellularity, and age of the fibroid. Degenerative submucous/intracavitary fibroids may display central low impedance blood flow signals. ${ }^{65,66}$ After initial transvaginal ultrasound, SIS is recommended for improved visualization of the thickness of overlying myometrium and surgical planning. ${ }^{67}$ Top differential diagnosis is an endometrial polyp, which is usually visualized as a hyperechogenic endometrial lesion with no continuity with the underlying myometrium. Contrary to leiomyoma scattered vascular pattern on color Doppler ultrasound, endometrial polyps show a single vascular pedicle.

Intramural fibroids are the most common fibroids, affecting about $40 \%$ of women after age of 35 years. ${ }^{3}$ If uncomplicated, they are visualized as homogenous round, well-defined myometrial lesions. Majority of intramural fibroids are asymptomatic; however, $25-30 \%$ of the patients may present with menorrhagia, polymenorrhea, menometrorrhagia, bloating, pressure effects,
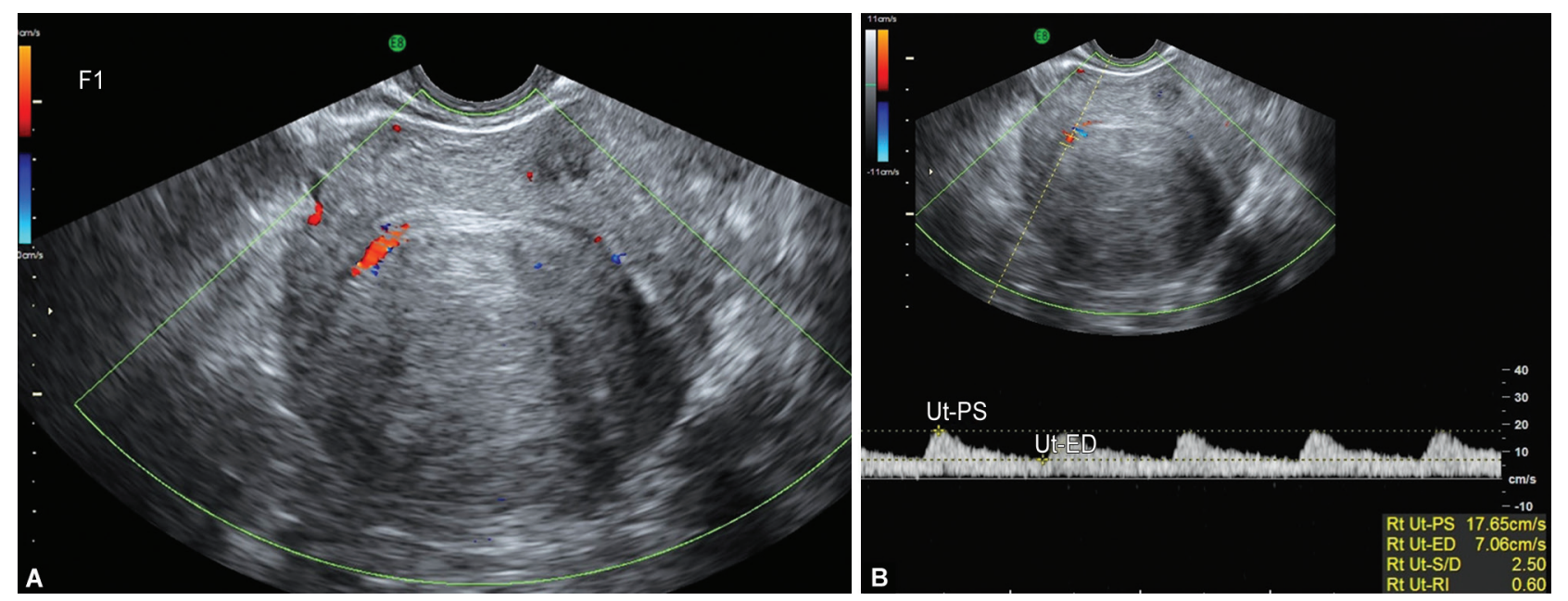

Figs 1 A and B: Transvaginal color Doppler image of a solitary intramural fibroid. (A) Note a well-delineated intramural fibroid with a regularly separated vessel within the pseudocapsule; (B) Pulsed Doppler waveform analysis reveals moderate vascular resistance signals (RI 0.60 )
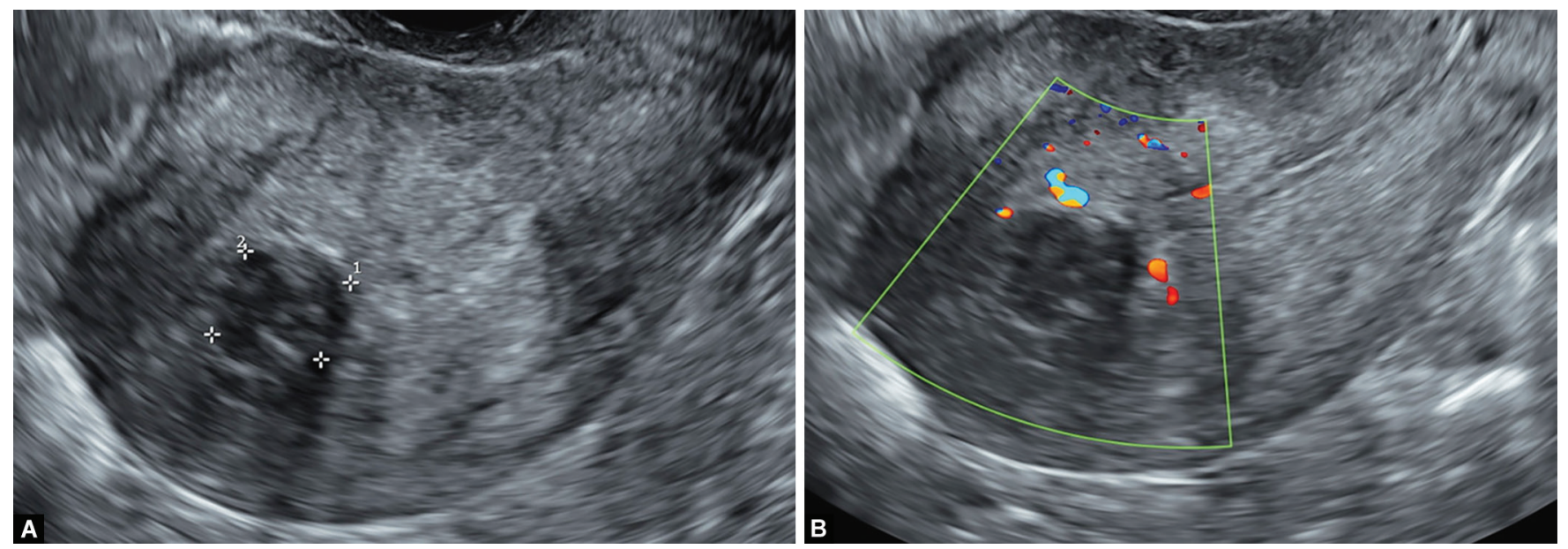

Figs $2 \mathrm{~A}$ and B: Transvaginal ultrasound of a hypoechoic fibroid in a patient with secondary infertility. (A) Hypoechoic fibroid measuring $1.3 \times$ $1.5 \mathrm{~cm}$ is visualized in the fundal area, impinging upon a nearby endometrium; (B) Color Doppler displays discrete peripheral blood flow signals 

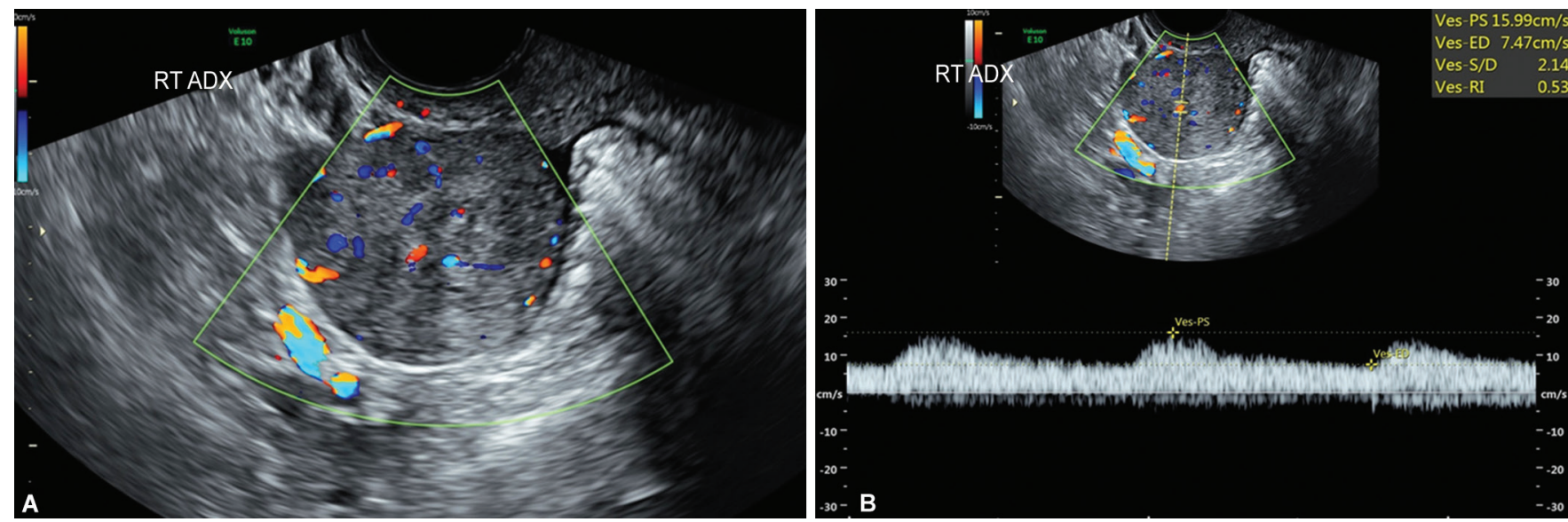

Figs $3 \mathrm{~A}$ and B: Transvaginal color Doppler image of a solid tumor in the right adnexal region in a primary infertile patient complaining of acute pelvic pain. (A) Solid mass is visualized in the right adnexal region. Transvaginal color Doppler image reveals scattered vascularity. The right ovary was visualized laterally from the lesion and was within the normal sonographic limits; (B) Spectral Doppler analysis reveals moderate impedance blood flow signals (RI 0.53). Comparison with transvaginal ultrasound which was performed 6 months earlier confirms prior diagnosis of a subserous fibroid. Laparoscopic surgery confirmed that the fibroid was twisted on its pedicle. Increased perfusion visualized within the pedunculated fibroid is consistent with necrosis which was confirmed by histology

dull ache, bloating, and/or pain..$^{3,64,65}$ Transabdominal ultrasound scan is necessary to obtain the overall size of the uterus, assess its contour, and leiomyoma locations, size, and echotexture changes.

Subserous fibroids are usually visualized as homogenous, round, well-defined masses protruding from the uterus with similar echogenicity as myometrium. Sometimes pedunculated myomas cannot be detected by transvaginal ultrasound, but only with transabdominal approach. In this case, color Doppler ultrasound enables visualization of the vessels in the leiomyoma stalk. Identification of the vascular resistance of these vessels may assist in identification of the uterine origin of the tumor. Rarely pedunculated fibroid may twit on its pedicle, infarct, and undergo necrosis. Eventually, they may detach and become infected. ${ }^{65,66}$ In these cases, pulsed Doppler ultrasound reveals increased vascularity accompanied with low vascular impedance signals (Fig. 3).

Different types of degenerative changes are associated with alteration in fibroid's echotexture. With aging, the leiomyoma may undergo different types of degenerative changes. Hyaline degeneration is considered the most common, affecting about $60-70 \%$ of the uterine fibroids. ${ }^{65,66}$ On ultrasound, it is recognized as loss of leiomyoma whorl appearance which occurs when the fibroid gradually outgrows its blood supply. When advanced, fibroids with hyaline degeneration may undergo fat degeneration, which is visualized as hyperechogenic well-delineated fatty deposits, with posterior attenuation (Fig. 4). Calcific degeneration occurs when calcium binds to phospholipids within the membrane of the necrotic cells. These changes are recognized as bright reflectors with posterior shadowing and may vary from focal areas to extensive calcifications, usually observed in older women (Fig. 5). ${ }^{65}$ Cystic degeneration is recognized as the presence of hypoechoic areas within the leiomyoma. Cystic spaces appear as round and well-demarcated sonolucent areas (Fig. 6). ${ }^{66}$ Although the majority of degenerating fibroids are asymptomatic, sometimes they may present with acute pelvic pain, leukocytosis, nausea, and vomiting.

\section{The Added Value of 3D Ultrasound}

Ultrasound has evolved so quickly and now has it all: from realtime imaging, through functional Doppler assessment to volume rendering. By providing multiplanar imaging, 3D ultrasound

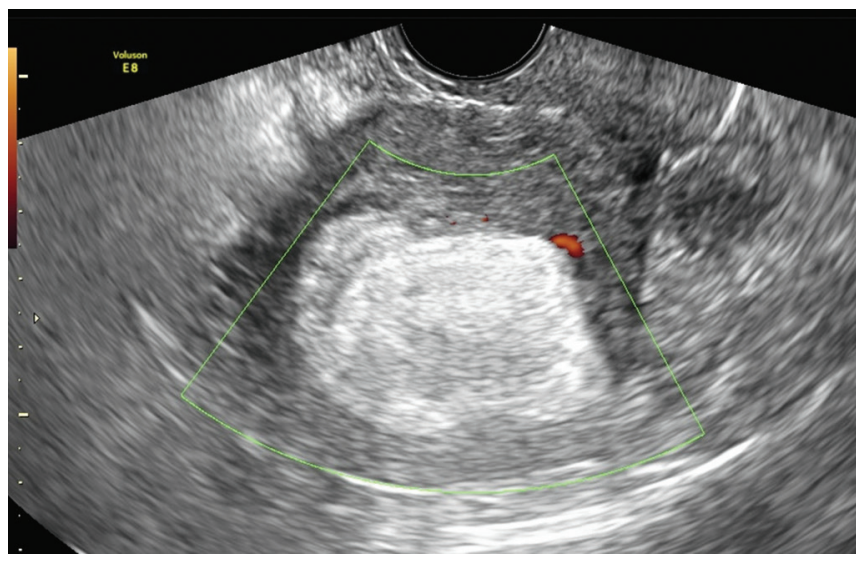

Fig. 4: Transvaginal color Doppler image of a fibroid with a welldelineated hyperechogenic area with posterior attenuation, suggestive of fat degeneration

not only gives an additional dimension to the uterine scan but also provides a similar quality and less expensive alternative to MRI. Automated volume acquisition minimizes the subjectivity of the ultrasound assessment and can be used for retrospective analysis ("reevaluation at any time from any view and any orientation"). ${ }^{64,65}$

In patients with enlarged uterus and multiple fibroids, tomographic ultrasound imaging (TUI) is recommended for improved mapping of the uterine fibroids. ${ }^{64}$ Simultaneous display of the coronal, sagittal, and transverse planes contributes to better localization and more accurate volume estimation of the uterine lesions. The volume display and OmniView improve the assessment of the continuity of the fibroids in different projections, leading to better concordance with intraoperative findings (Fig. 7).

Saline infusion sonography is a minimally invasive ultrasound technique that involves infusion of a small volume of sterile saline into the uterine cavity, followed by a pelvic ultrasound evaluation. ${ }^{67}$ Saline acts as a negative contrast medium which clearly delineates hyperechogenic endometrial lining (Fig. 8). The procedure can be performed under the guidance of $2 \mathrm{D}$ and $3 \mathrm{D}$ ultrasound. 3D SIS can precisely depict submucous and intracavitary fibroids, 

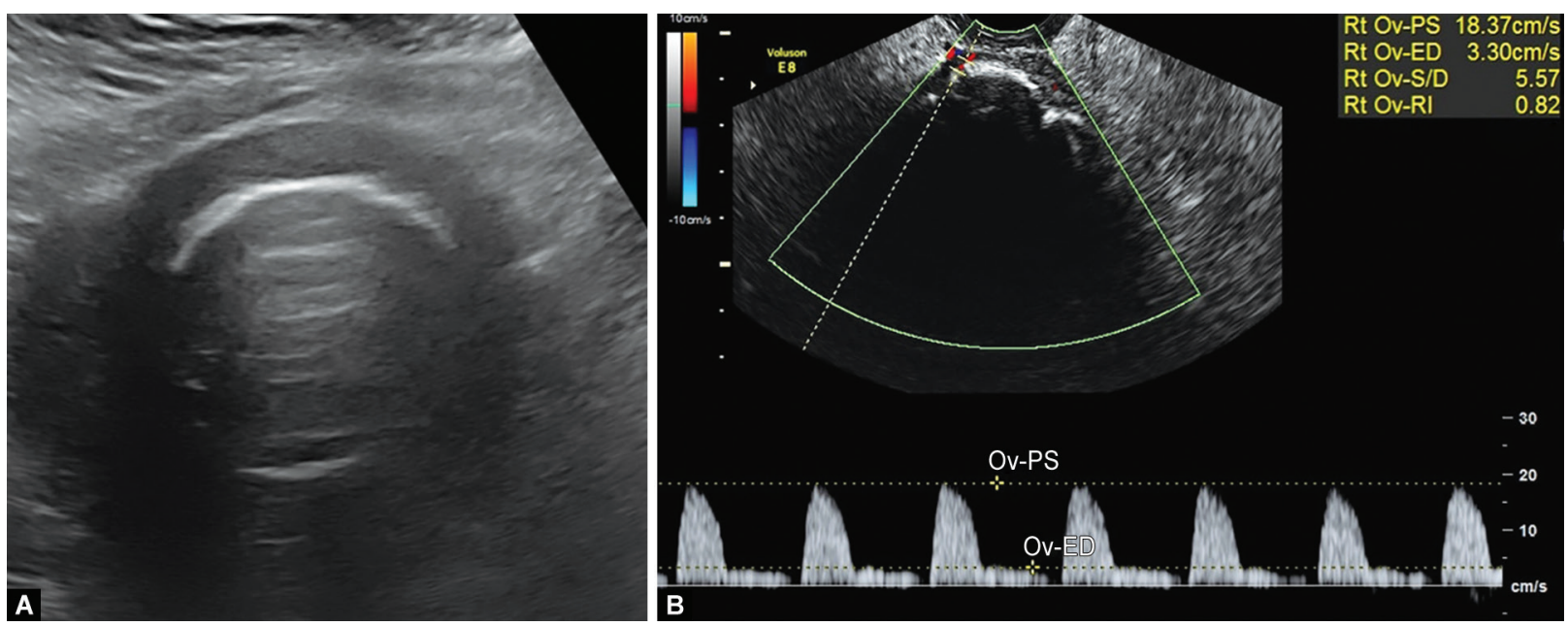

Figs 5A and B: Transabdominal and transvaginal images of calcific degeneration. (A) Transabdominal ultrasound image of an intramural fibroid with calcific degeneration, recognized as ellipsoid-shaped bright signals; (B) Transvaginal color Doppler image of a fibroid with "popcorn-like" appearance of calcification. High-impedance blood flow signals (RI 0.82) are obtained from the peripheral vessels

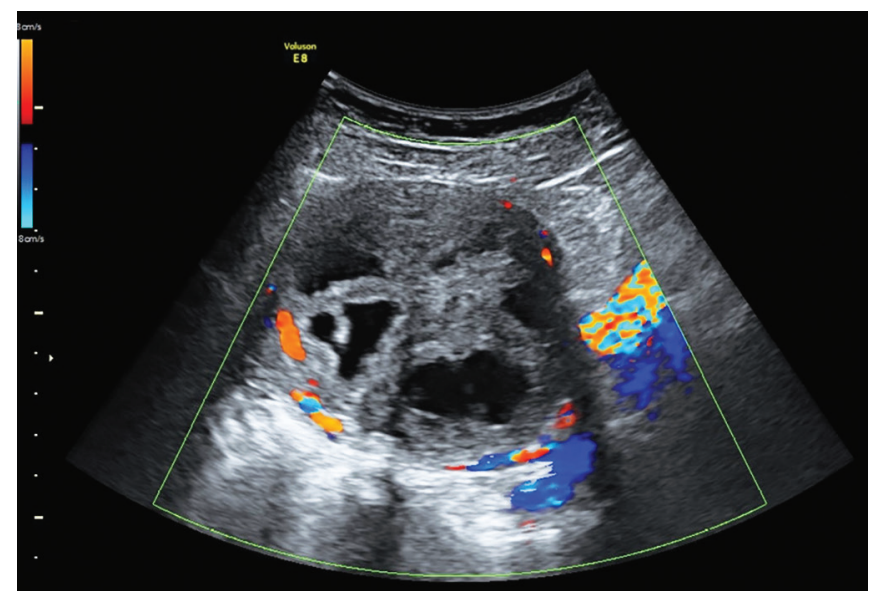

Fig. 6: Transabdominal color Doppler image illustrating cystic degeneration of a huge subserous fibroid. Color Doppler reveals regularly separated blood vessels at its periphery

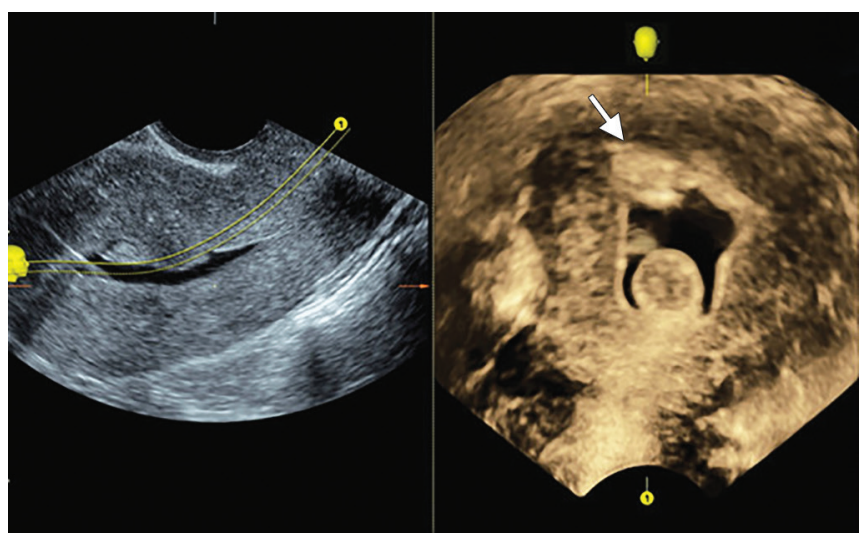

Fig. 8: Saline infusion sonography of a patient with a small intracavitary fibroid at the level of the internal cervical os. Hyperechogenic fundal polyp, shown by an arrow, is obstructing the opening of the right fallopian tube into the uterine cavity
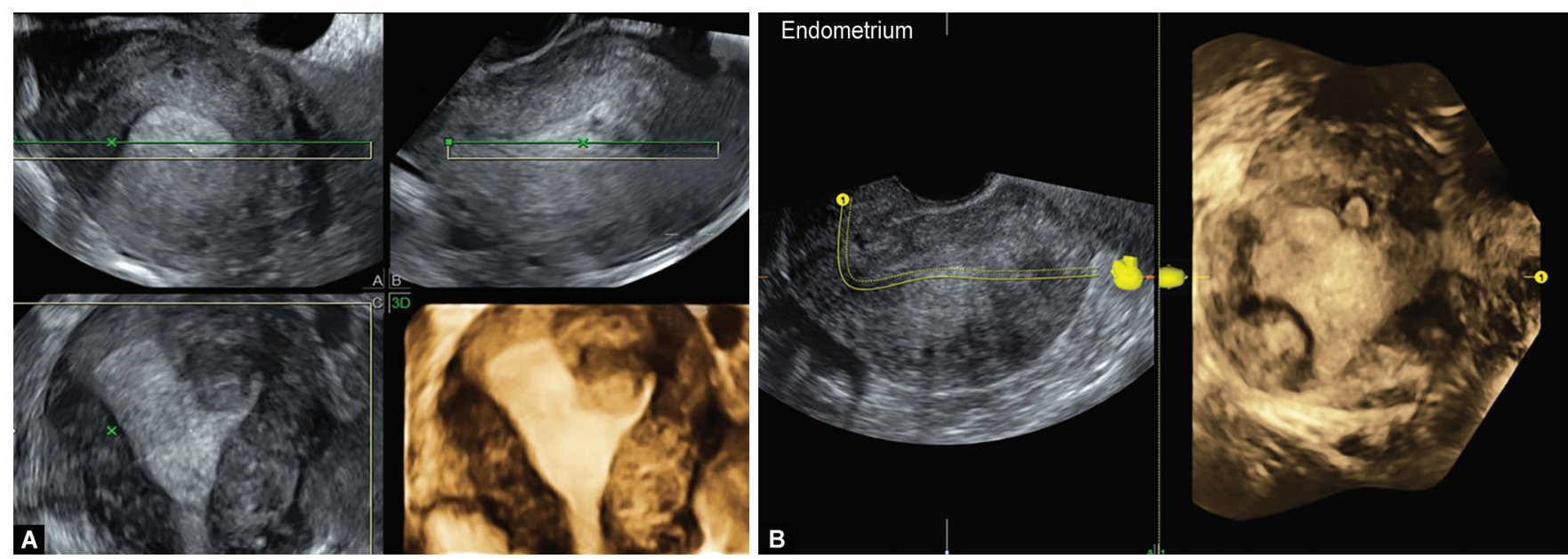

Figs 7A and B:Transvaginal 3D ultrasound of a submucous fibroid in an infertile patient. (A) Multiplanar view and surface rendering of a submucous fibroid impinging on the uterine cavity and blocking the intramural portion of the fallopian tube; (B) The same patient assessed by OmniView 

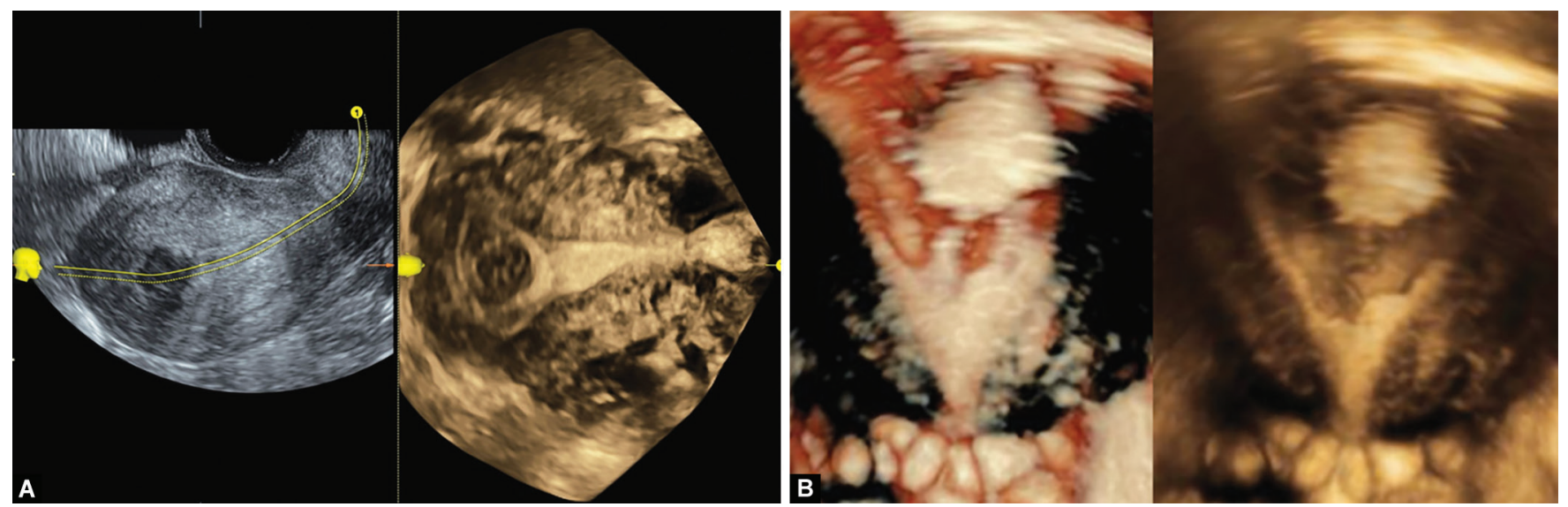

Figs $9 \mathrm{~A}$ and B: 3D imaging and 3D saline infusion sonography of a submucous fibroid in a secondary infertile patient. (A) OmniView reveals a hypoechogenic intracavitary fibroid; (B) 3D saline infusion sonography of the same patient. Sonographic finding of intracavitary fibroid was confirmed by hysteroscopy
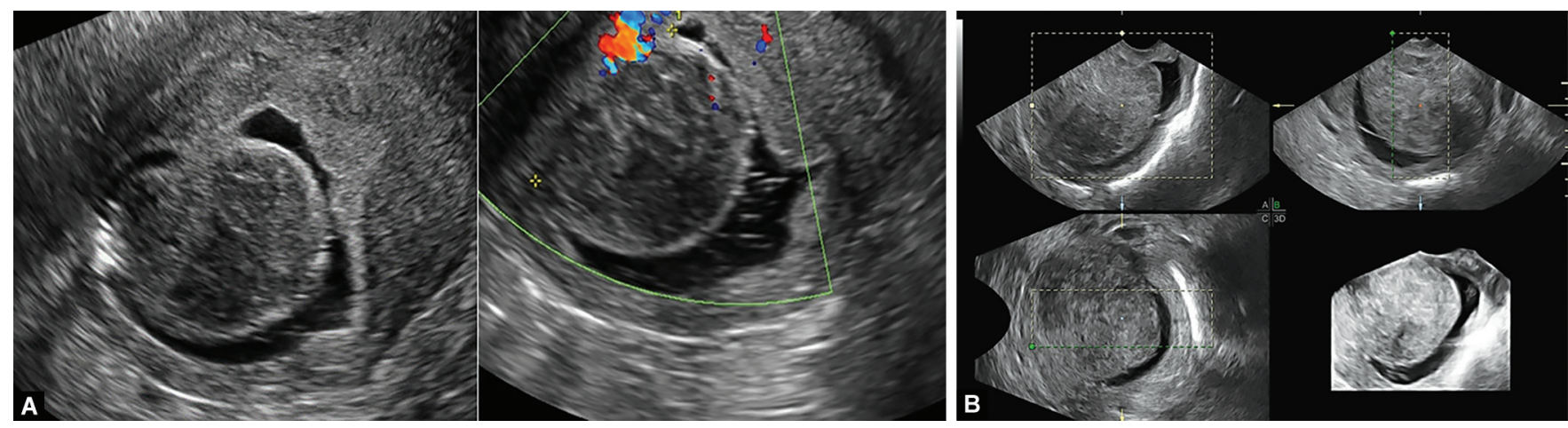

Figs $10 A$ and $B: 2 D$ and 3D saline infusion sonography of an intracavitary fibroid in an infertile patient complaining of metrorrhagia. (A) $2 D$ saline infusion sonography of a huge intracavitary fibroid. Color Doppler reveals vascularized pedicle; (B) 3D saline infusion sonography of another patient with a huge intracavitary fibroid. A protruding fibroid has a wide base compared to a relatively thin connection pedicle of a fibroid displayed in figure $\mathrm{A}$
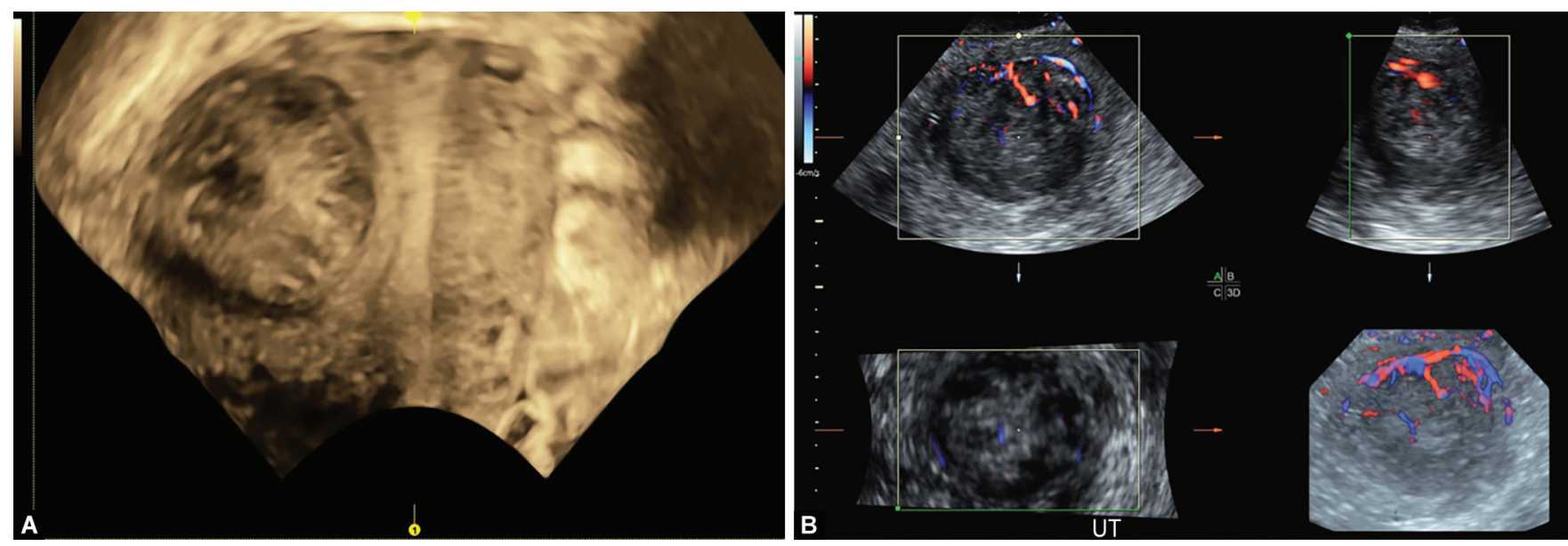

Figs 11A and B:3D ultrasound and 3D color Doppler image of an intramural fibroid. (A) 3D ultrasound image of an intramural fibroid; (B) 3D color/ power Doppler angiography reveals regularly separated peripheral vessels, typical for a benign uterine growth

determine their size and extent of protrusion, which is important for planning of a hysteroscopic resection (Fig. 9.). When the entire fibroid is visualized arising from the pedicle, the lesion is classified as intracavitary (Fig. 10). 3D SIS is reported as superior to hysteroscopy for determining the depth of fibroid penetration to the endometrium and/or myometrium. ${ }^{67}$
It is well-known that malignant tumors are characterized with abundant and disorganized blood flow patterns, whereas benign lesions show regular, predominantly peripheral vessel distribution (Fig. 11) ${ }^{68-70}$ Neovascularization represents a network of capillaries and larger vessels, whose wall is devoid of smooth muscle cells and elastic fibers, which on spectral Doppler analysis manifests as 


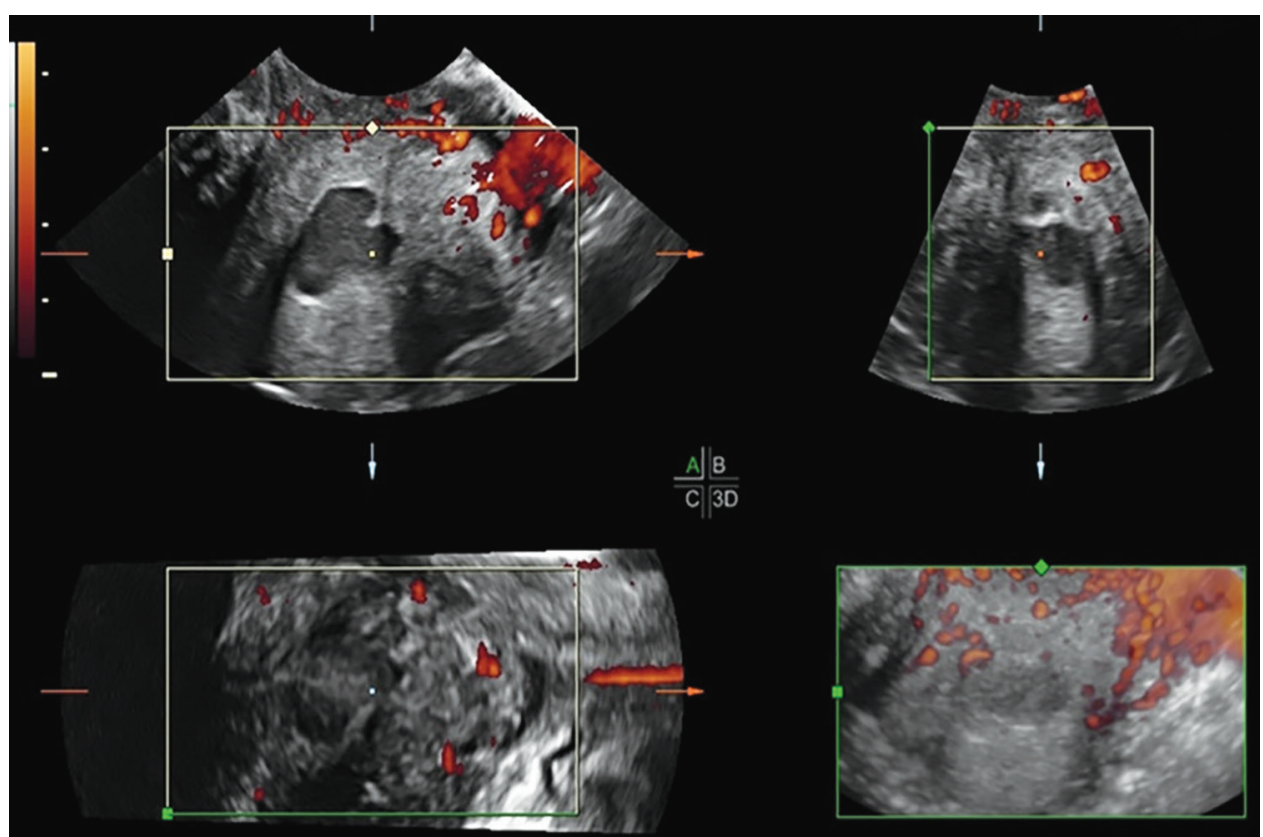

Fig. 12: 3D power Doppler image of a complex uterine mass in patient with increased size of the uterus in postmenopause. Irregular branching of the vessels with uneven diameter is suggestive of a malignant uterine lesion. Uterine leiomyosarcoma was confirmed by histology

reduced vascular impedance. Vascular resistance measured by angle independent Doppler parameters, the resistance (RI) and pulsatility index (PI), is largely dependent on the fraction of arterioles in the microcirculation. ${ }^{71}$ Reported variations in blood flow in malignant tumors after radiotherapy suggest that the same technology has a potential to predict a response of a tumor to treatment. ${ }^{72} 3 \mathrm{D}$ power Doppler angiography enables objective assessment of the vessels' density and quantification of the amount of blood within a volume of the tumor tissue, leading to a new concept of "virtual tumor biopsy." ${ }^{173}$ The use of contrast agents is another possibility for enhancing the 3D power Doppler examination by increasing the detection rate of capillaries with small diameter.

Although uterine leiomyosarcoma is a rare tumor, accounting for only $1-3 \%$ of all genital tumors, it is characterized with poor prognosis due to early dissemination. ${ }^{69,74-76}$ As gynecologists are more frequently choosing to use conservative treatment for uterine fibroids (e.g., pharmacologic treatment, uterine fibroid embolization, MR-guided focused ultrasound, and ultrasoundguided fibroid sclerozation), uterine leiomyosarcoma may become more common in the near future. ${ }^{77}$ Clinically, this malignant tumor presents with atypical signs and symptoms, similar to the uterine leiomyoma such as abnormal uterine bleeding, palpable pelvic mass, lower abdominal pressure, and increase in size of the uterus after the onset of menopause. ${ }^{64,78}$ On ultrasound, leiomyosarcoma is presented as solid or complex tumor. Color Doppler reveals irregular and randomly dispersed vessels with high velocity and low vascular impedance. ${ }^{78}$ Demonstration of the irregular branching of the vessels with uneven diameter, microaneurysms, and stenosis are typical 3D power Doppler angiography features of the leiomyosarcoma neovascularization (Fig. 12). ${ }^{79}$

\section{ConcLusion}

While there is a consensus that submucous uterine fibroids distorting the uterine cavity are associated with infertility and early pregnancy loss, the clinical relationship of intramural fibroids and infertility remains unclear. Because the effect of fibroids on implantation may not be reflected on the endometrium overlying the submucous or intramural fibroids, future studies should focus on the assessment of global effects such as alteration of vasoconstriction factors, fibrinolytic and anticoagulant activity, and endometrial gene expression. ${ }^{80}$

Combining the advantages of multiple imaging modalities: ultrasound as a noninvasive, nonirradiation, and inexpensive method, and volume acquisition known from CT and MR imaging technologies, 3D ultrasound and 3D power Doppler angiography have become valuable diagnostic tools for the assessment of uterine fibroids. Despite many advances in molecular and genetic linkage analysis, efficient diagnosis by high-resolution ultrasound imaging, introduction of minimally invasive techniques of leiomyoma embolization, uterine artery occlusion, and high focused ultrasound therapy, an integration of knowledge is required to assist in improved understanding of this most common gynecologic neoplasm of reproductive age women. Identification of the causes of the uterine fibroids is difficult because of their phenotypic complexity and variability. Therefore, combination of the basic science, genetic, clinical, and high-resolution multiplanar imaging studies is required for a better understanding of the etiopathogenesis and management of these common uterine tumors.

\section{References}

1. Haney AF. Leiomyomata. In: Danforth's Obstetrics and Gynecology, 10th ed. Philadelphia, PA: Lippincott Williams \& Wilkins; 2003.

2. Day Baird D, Dunson DB, Hill MC. et al. High cumulative incidence of uterine leiomyoma in black and white women: ultrasound evidence. Am J Obstet Gynecol 2003;188(1):100-107. DOI: 10.1067/mob.2003.99.

3. Laughlin SK, Schroeder JC, Baird DD. New directions in the epidemiology of uterine fibroids. Semin Reprod Med 2010;28(3): 204-217. DOI: 10.1055/s-0030-1251477.

4. Salem S, Wilson SR. Gynecologic ultrasound. In: Diagnostic Ultrasound, 3rd ed. St. Louis, MO: Elsevier Mosby, vol. 1; 2005. 
5. Schwartz SM. Epidemiology of uterine leiomyomata. Clin Obstet Gynecol 2001;44(2):316-326. DOI: 10.1097/00003081-20010600000018.

6. Wise LA, Palmer JR, Harlow BL, et al. Risk of uterine leiomyomata in relation to tobacco, alcohol and caffeine consumption in the Black Women's Health Study. Hum Reprod 2004;19(8):1746-1754. DOI: 10.1093/humrep/deh309.

7. Levine DJ, Berman JM, Harris M, et al. Sensitivity of myoma imaging using laparoscopic ultrasound compared with magnetic resonance imaging and transvaginal ultrasound. J Minim Invasive Gynecol 2013;20(6):770-774. DOI: 10.1016/j.jmig.2013.04.015.

8. Moshesh M, Peddada SD, Cooper T, et al. Intraobserver variability in fibroid size measurements. J Ultrasound Med 2014;33(7):1217-1224. DOI: 10.7863/ultra.33.7.1217.

9. Mavrelos D, Ben-Nagi J, Holland T, et al. The natural history of fibroids. Ultrasound Obstet Gynecol 2010;35(2):238-242. DOI: 10.1002/ uog.7482.

10. Poder L. Ultrasound evaluation of the uterus. In: Ultrasonography in Obstetrics and Gynecology, 5th ed., Philadelphia, PA: Elsevier; 2008.

11. Parker WH. Etiology, symptomatology, and diagnosis of uterine myomas. Fertil Steril 2007;87(4):725-736. DOI: 10.1016/ j.fertnstert.2007.01.093.

12. Cloke B, Brosens J, Brosens I. Leiomyomata and reproductive function. In: Uterine Leiomyomata. Pathogenesis and Management, 1st ed., London, UK: Taylor \& Francis; 2006. pp. 107-116.

13. Pritts EA. Fibroids and infertility: a systematic review of the evidence. Obstet Gynecol Surv 2001;56(8):483-491. DOI: 10.1097/00006254200108000-00022.

14. Pritts EA, Parker WH, Ikuve DL. Fibroids and infertility: an updated systematic review of the evidence. Fertil Steril 2009;91(4):1216-1223. DOI: 10.1016/j.fertnstert.2008.01.051.

15. Yoshino O, Hayashi T, Osuga Y, et al. Decreased pregnancy rate is linked to abnormal uterine peristalsis caused by intramural fibroids. Hum Reprod 2010;25(10):2475-2479. DOI: 10.1093/humrep/deq222.

16. Yan $L$, Ding $L, L i C$, et al. Effect of fibroids not distorting the endometrial cavity on the outcome of in vitro fertilization treatment: a retrospective cohort study. Fertil Steril 2014;101(3):716-721. DOI: 10.1016/j.fertnstert.2013.11.023.

17. Practice Committee of the American Society for Reproductive Medicine. Myomas and reproductive function. Fertil Steril 2004;82(1):S111-S116. DOI: 10.1016/j.fertnstert.2004.05.061.

18. Buttram VC, Reiter RC. Uterine leiomyomata: etiology, symptomatology, and management. Fertil Steril 1981;36(4):433-445. DOI: 10.1016/S0015-0282(16)45789-4.

19. Vander Werff BJ, Hagen-Ansert S. Pathology of the uterus. In: Ultrasonography in Obstetrics and Gynecology, 5th ed., Philadelphia, PA: Elsevier; 2008.

20. Ito $\mathrm{F}$, Kawamura N, Ichimura $\mathrm{T}$, et al. Ultrastructural comparison of uterine leiomyoma cells from the same myoma nodule before and after gonadotropin-releasing hormone agonist treatment. Fertil Steril 2001;75(1):125-130. DOI: 10.1016/S0015-0282(00)01660-5.

21. Kurjak A, Kupesic S. Effetto degli analoghi del GnRH sul flusso ematico negli organi ginecologici. In: Nuovi aspetti clinici dei GnRH analoghi. Roma: CIC Edizioni Internazionali; 1994.

22. Kupesic $S$, Kurjak A. Blood flow in gynecological organs treated by GnRH agonists. Book of abstracts. XIV FIGO World Congress, Montreal, Canada, September 25-30. IJGOAL 1994;46(Suppl 2):60.

23. Garcia Velasco JA, Kupesic S, Mrazek M, et al. Synchronization of the follicle cohort with the GnRH antagonist Degarelix: a randomized assessor blind, placebo controlled trial. Fertil Steril 2008;90:234. DOI: 10.1016/j.fertnstert.2008.07.569.

24. Bourlev V, Pavlovitch S, Stygar D, et al. Different proliferative and apoptotic activity in peripheral versus central parts of human uterine leiomyomas. Gynecol Obstet Invest 2003;55(4):199-204. DOI: 10.1159/000072074.

25. Wei JJ, Zhang XM, Chiriboga L, et al. Spatial differences in biologic activity of large uterine leiomyomata. Fertil Steril 2006;85(1):179-187. DOI: 10.1016/j.fertnstert.2005.07.1294.
26. Dapunt O. Studies on the structure of the myoma capsule. Arch Gynecol 1965;202(1):492-494. DOI: 10.1007/bf00672205.

27. Lindner V, Reidy MA. Proliferation of smooth muscle cells after vascular injury is inhibited by an antibody against basic fibroblast growth factor. Proc Natl Acad Sci U S A 1991;88(36):3739-3743. DOI: 10.1073/pnas.88.9.3739.

28. Stewart EA, Nowak RA. Leiomyoma-related bleeding: a classic hypothesis updated for the molecular era. Hum Reprod Update 1996;2(4):295-306. DOI: 10.1093/humupd/2.4.295.

29. Olmos Gring AO, Lora V, Ferreira GD, et al. Protein expression of estrogen receptors $\alpha$ and $\beta$ and aromatase in myometrium and uterine leiomyoma. Gynecol Obstet Invest 2012;73(3):113-117. DOI: 10.1159/000330700.

30. Ishikawa H, Ishi V, AnnSerna V, et al. Progesterone is essential for maintenance and growth of uterine leiomyoma. Endocrinology 2010;151(6):2433-2442. DOI: 10.1210/en.2009-1225.

31. Barbarisi A, Petillo O, Di Lieto A, et al. 17-beta estradiol elicits an autocrine leiomyoma cell proliferation: evidence for a stimulation of protein kinase-dependent pathway. J Cell Physiol 2001;186(3): 414-424. DOI: 10.1002/1097-4652(2000)9999:999<000::AIDJCP1040>3.0.CO;2-E.

32. Park S, Ramachandran S, Kwon S, et al. Upregulation of ATP-sensitive potassium channels for estrogen-mediated cell proliferation in human uterine leiomyoma cells. Gynecol Endocrinol 2008;24(5): 250-256. DOI: 10.1080/09513590801893315.

33. Rein MS, Barbieri RL, Friedman AJ. Progesterone: a critical role in the pathogenesis of uterine myomas. Am J Obstet Gynecol 1995;172(1):14-18. DOI: 10.1016/0002-9378(95)90077-2.

34. Andersen J. Growth factors and cytokines in uterine leiomyomas. Semin Reprod Endocrinol 1996;14(3):269-282. DOI: 10.1055/s-20071016336.

35. Kurjak A, Kupesic S, Miric D. Transvaginal color Doppler in the assessment of uterine blood flow changes during the pregnancy in patients with fibroids. J Perinat Med 1991;19(Suppl 2):81.

36. Kurjak A, Predanic M, Kupesic S, et al. Transvaginal color Doppler in the study of early pregnancies associated with fibroids. J Matern Fetal Invest 1992;2:81-83.

37. Rosati P, Exacoustòs C, Mancuso S. Longitudinal evaluation of uterine myoma growth during pregnancy. A sonographic study. J Ultrasound Med 1992;11(10):511. DOI: 10.7863/jum.1992.11.10.511.

38. Strobelt N, Ghidini A, Cavallone M, et al. Natural history of uterine leiomyomas in pregnancy. J Ultrasound Med 1994;13(5):399. DOI: 10.7863/jum.1994.13.5.399.

39. Aharoni A, Reiter A, Golan D, et al. Patterns of growth of uterine leiomyomas during pregnancy. A prospective longitudinal study. Br J Obstet Gynaecol 1988;95(5):510. DOI: 10.1111/j.1471-0528.1988. tb12807.x.

40. Klatsky PC, Tran ND, Caughey AB, et al. Fibroids and reproductive outcomes: a systematic literature review from conception to delivery. Am J Obstet Gynecol 2008;198(4):357. DOI: 10.1016/j.ajog.2007.12. 039.

41. Chen $\mathrm{YH}$, Lin HC, Chen SF, et al. Increased risk of preterm births among women with uterine leiomyoma: a nationwide population-based study. Hum Reprod 2009;24(12):3049-3056. DOI: 10.1093/humrep/ dep320.

42. Lam SJ, Best S, Kumar S. The impact of fibroid characteristics on pregnancy outcome. Am J Obstet Gynecol 2014;211(4):395. DOI: 10.1016/j.ajog.2014.03.066.

43. Shavell VI, Thakur M, Sawant A, et al. Adverse obstetric outcomes associated with sonographically identified large uterine fibroids. Fertil Steril 2012;97(1):107. DOI: 10.1016/j.fertnstert.2011. 10.009 .

44. Roberts WE, Fulp KS, Morrison JC, et al. The impact of leiomyomas on pregnancy. Aust N Z J Obstet Gynaecol 1999;39(1):43-47. DOI: 10.1111/j.1479-828X.1999.tb03442.x.

45. Davis JL, Ray-Mazumder S, Hobel CJ, et al. Uterine leiomyomas in pregnancy: a prospective study. Obstet Gynecol 1990;75(1): $41-44$. 
46. Vergani $P$, Ghidini A, Strobelt N, et al. Do uterine leiomyomas influence pregnancy outcome? Am J Perinatol 1994;11(5):356-568. DOI: $10.1055 / \mathrm{s}-2007-994554$.

47. Coronado GD, Marshall LM, Schwartz SM. Complications in pregnancy, labor, and delivery with uterine leiomyomas: a population-based study. Obstet Gynecol 2000;95(5):764-769. DOI: 10.1097/00006250200005000-00025.

48. Winer-Muram HT, Muram D, Gillieson MS. Uterine myomas in pregnancy. J Can Assoc Radiol 1984;35(2):168-170. DOI: 10.1097/00006254-198402000-00007.

49. Forssman L. Distribution of blood flow in myomatous uteri as measured by locally injected 133Xenon. Acta Obstet Gynecol Scand 1976;55(2):101-104. DOI: 10.3109/00016347609156794.

50. Heinonen PK, Saarikoski S, Pystynen P. Reproductive performance of women with uterine anomalies. An evaluation of 182 cases. Acta Obstet Gynecol Scand 1982;61(2):157-162. DOI: 10.3109/00016348209156548.

51. Worthen NJ, Gonzalez F. Septate uterus: sonographic diagnosis and obstetric complications. Obstet Gynecol 1984;64(3 Suppl):34S-38S. DOI: 10.1097/00006250-198409001-00009.

52. Phelan JP. Myomas and pregnancy. Obstet Gynecol Clin North Am 1995;22(4):801-805.

53. Szamatowicz J, Laudanski T, Bulkszas B, et al. Fibromyomas and uterine contractions. Acta Obstet Gynecol Scand 1997;76(10):973-976. DOI: 10.3109/00016349709034912.

54. Hasan F, Arumugam K, Sivanesaratnam V. Uterine leiomyomata in pregnancy. Int J Gynaecol Obstet 1991;34(1):45-48. DOI: 10.1016/0020-7292(91)90537-F.

55. Sheiner E, Biderman-Madar T, Katz M, et al. Higher rates of tachysystole among patients with clinically apparent uterine leiomyomas. Am J Obstet Gynecol 2004;191(3):945-948. DOI: 10.1016/j.ajog.2004.05.060.

56. Koike $\mathrm{T}$, Minakami $\mathrm{H}$, Kosuge $\mathrm{S}$, et al. Uterine leiomyoma in pregnancy: its influence on obstetric performance. J Obstet Gynaecol Res 1999;25(5):309-313. DOI: 10.1111/j.1447-0756.1999.tb01168.x.

57. Vergani $P$, Locatelli $A$, Ghidini $A$, et al. Large uterine leiomyomata and risk of cesarean delivery. Obstet Gynecol 2007;109(2 Pt 1):410-414. DOI: 10.1097/01.AOG.0000250470.78700.f0.

58. Michels KA, Velez Edwards DR, Baird DD, et al. Uterine leiomyomata and cesarean birth risk: a prospective cohort with standardized imaging. Ann Epidemiol 2014;24(2):122-126. DOI: 10.1016/ j.annepidem.2013.10.017.

59. Kupesic S, Plavsic BM. Sonography of uterine leiomyomata. In: Uterine Leiomyomata. Pathogenesis and Management, 1st ed., London, UK: Taylor \& Francis; 2006. pp. 139-151.

60. Stephenson SR. Benign diseases of female pelvis. In: Diagnostic Medical Sonography: Obstetrics and Gynecology, 3rd ed., Baltimore, MD; Philadelphia, PA: Wolters Kluwer, Lippincott Williams and Wilkins; 2012. pp. 175-211.

61. Stewart EA, Nowak RA. New concepts in the treatment of uterine leiomyomas. Obstet Gynecol 1998;92(4 Pt 1):624-627. DOI: 10.1016/ S0029-7844(98)00243-9.

62. Vizza E, Motta PM. The skeleton fibrous and muscolar of the uterus. In: CIC Edizioni Internazionali ed. Atti LXXVII Congresso SIGO. S.r.I. Rome: CIC Edit Int.; 2001. pp. 47-49.

63. Kupesic Plavsic S, Montgomery L, Tullius TG, et al. Uterine fibroids. In: Kupesic Plavsic S, ed. Step by Step through OB GYN Case Studies, 1st ed., London, New Delhi, Panama City, St. Louis: Jaypee; 2014. pp. 183-199.

64. Kupesic S, Kurjak A, Baston K. Color Doppler and three-dimensional ultrasound of the uterine lesions. In: Kupesic S, ed. Color Doppler and Three-Dimensional Ultrasound in Gynecology, Infertility and Obstetrics. New Delhi: Jaypee Brothers; 2011. pp. 22-33.
65. Kupesic Plavsic S, Honemeyer U, Kurjak A. Uterine lesions: advances in ultrasound diagnosis. In: Donald School Textbook of Ultrasound in Obstetrics and Gynecology Kurjak A, Chervenak F, ed. London, New Delhi, Panama City, St. Louis: Jaypee Brothers Medical Publishers Ltd; 2017. pp. 838-859.

66. Kupesic Plavsic S, Sparac V. Submucosal uterine fibroid. In: Reddy SY, Mendez M, Kupesic Plavsic S., ed. Illustrated OB GYN Problems, 1st ed., New Delhi, London, Philadelphia, Panama: Jaypee Brothers Medical Publishers Ltd; 2018. in press.

67. Padilla O, Arya S, Noble LS, et al. Saline infusion sonography: tips and tricks for improved visualization of the uterine cavity. Donald School J Ultrasound Obstet Gynecol 2018;12(1):1-20. DOI: 10.5005/ jp-journals-10009-1545.

68. Kurjak A, Kupesic S, Jukic S. Successful differentiation between fibroid and uterine sarcoma by TVCD. Fifth World Congress of Ultrasound in Obstetrics and Gynecology. Book of abstracts. Ultrasound Obstet Gynecol 1995;6(Suppl 2):112.

69. Kupesic S, Kurjak A. Color Doppler assessment of uterine leiomyoma and sarcoma. In: Kurjak A, Kupesic S, ed. An Atlas of transvaginal color Doppler. London-New York: Parthenon Publishing; 2000. p. 179.

70. Honemeyer U, Ross RJ, Barnard J, et al. Recurrent leiomyomatosis disseminata: sonographic and laparoscopic correlation. Donald School J Ultrasound Obstet Gynecol 2012;6(3):327-332. DOI: 10.5005/ jp-journals-10009-1256.

71. Kidron D, Berheim J, Aviram I, et al. Resistance to blood flow in ovarian tumors: correlation between resistance index and histological pattern of vascularization. Ultrasound Obstet Gynecol 1999;13(6):425-430. DOI: 10.1046/j.1469-0705.1999. 13060425.x.

72. Prompuntagorn C, Saldivar JS, Kupesic Plavsic S. Ultrasound assessment of ovarian function following radiation therapy. Donald School J Ultrasound Obstet Gynecol 2014;8(3):288-292. DOI: 10.5005/ jp-journals-10009-1367.

73. Kupesic $S$, Kurjak A, Bjelos D. The assessment of uterine lesions. In: Kurjak A, Kupesic S, ed. Clinical Application of 3D Sonography. London-New York: Parthenon Publishing; 2000. pp. 55-67.

74. Kurjak A, Kupesic S, Shalan H, et al. Uterine sarcoma: a report of 10 cases studied by transvaginal color and pulsed Doppler sonography. Gynecol Oncol 1995;59(3):342-346. DOI: 10.1006/gyno. 1995.9965

75. Kupesic S, Kurjak A. Uterine sarcoma. In: Kurjak A, Fleischer A, ed. Doppler Ultrasound in Gynecology. New York: Parthenon Publishing; 1998. pp. 125-132.

76. Ortiz C, Mendez MD, Padilla O, et al. Leiomyosarcoma. In: Reddy SY, Mendez M, Kupesic Plavsic S, ed. Illustrated OB GYN Problems, 1st ed., New Delhi, London, Philadelphia, Panama: Jaypee Brothers Medical Publishers Ltd; 2018, in press.

77. Ljubic A, Bozanovic T. Uterine fibroid. In: Donald School Textbook of Ultrasound in Obstetrics and Gynecology Kurjak A, Chervenak F, ed. London, New Delhi, Panama City, St. Louis: Jaypee Brothers Medical Publishers Ltd; 2017. pp. 859-874.

78. Exacoustos $C$, Romanini ME, Amadio A, et al. Can gray-scale and color Doppler sonography differentiate between uterine leiomyosarcoma and leiomyoma? J Clin Ultrasound 2007;35(8):449-457. DOI: 10.1002/ jcu.20386.

79. Aragon $\mathrm{L}$, Terreros $\mathrm{D}, \mathrm{Ho} \mathrm{H}$, et al. Ultrasound imaging of ovarian angiosarcoma. J Clin Ultrasound 2011;39(6):351-355. DOI: 10.1002/ jcu.20821.

80. Rackow BW, Taylor HS. Submucous uterine leiomyomas have a global effect on molecular determinants of endometrial receptivity. Fertil Steril 2010;93(6):2027-2034. DOI: 10.1016/ j.fertnstert.2008.03.029. 